\title{
Factors and Causes of Puerperal Sepsis in Kilimanjaro, Tanzania: A Descriptive Study among Postnatal Women who Attended Kilimanjaro Christian Medical Centre
}

\author{
Debora C. Kajegukaa, Neema Reuben Mrema ${ }^{a}$, Akili Mawazob, Rosemary Malya, ${ }^{a, c}$ \\ Maseke R. Mgaboa,d \\ aFaculty of Medicine, Department of Microbiology and Immunology, Kilimanjaro Christian Medical University College, Moshi, Tanzania, bFaculty of \\ Medicine, Department of Microbiology and Immunology, School of Medicine, Muhimbili University of Health and Allied Sciences, Dar es Salaam, \\ Tanzania, 'Department of Nursing, Kilimanjaro Christian Medical University College, Moshi, Tanzania, 'Department of Population Studies, Institute of \\ Rural Development Planning \\ Correspondence to Debora C. Kajeguka (dkajeguka@gmail.com )
}

\begin{abstract}
Background: Puerperal sepsis is the major cause of maternal morbidity and mortality worldwide. About $94 \%$ of maternal mortality occur in low and middle-income countries including Tanzania.

Objective: To estimate the prevalence, document factors and causes of puerperal sepsis among postnatal women who attended postnatal care in Kilimanjaro Christian Medical Centre Hospital in the year 2015.

Methodology: A descriptive cross-sectional study was carried out at Kilimanjaro Christian Medical Centre, Tanzania. A total of 183 medical records of attendance in 2015 were used for the study. Information about the isolated organism in culture was retrieved from the Laboratory Information System.

Results: The prevalence of puerperal sepsis was $11.5 \%(21 / 183)$. The most common factors and causes of puerperal sepsis included caesarean section $66.7 \%(14 / 21)$, postpartum haemorrhage $57.1 \%(12 / 21)$, moderate to severe anaemia $61.9 \%(13 / 21)$, prolonged labour $76.2 \%(16 / 21)$ and bacterial infection $90.5 \%(19 / 21)$. The difference was significant at $p<.05$. The most bacteria species isolated among women with puerperal sepsis was Staphylococcus spp 50.0\% (7/14), Escherichia 28.6\% (4/14) and Streptococcus spp $21.4 \%$ (3/14).

Conclusion: Puerperal sepsis is prevalent (1 1.5\%) at Kilimanjaro Christian Medical Centre. Staphylococcus spp was found to be a predominant isolate which causes puerperal sepsis followed by E. coli and Streptococcus spp.
\end{abstract}

\section{BACKGROUND}

Puerperal sepsis is the major cause of maternal morbidity and mortality worldwide while about $94 \%$ of maternal mortality occur in low and middleincome countries. ${ }^{1}$ Puerperal sepsis is among the preventable conditions in all settings. ${ }^{2}$ World health organization (WHO) defines puerperal sepsis as infection of the genital tract occurring at any time between the onset of rupture of membranes or labour and the 42 days (6 weeks) after delivery in which 2 or more of the following are present: pelvic pain, fever, abnormal vaginal discharge, abnormal smell/ foul odour discharge or delay in uterine involution. ${ }^{3}$ Puerperal sepsis causes $10.7 \%$ of maternal deaths and it is one of the 5 common causes of maternal mortality worldwide. ${ }^{4}$ Despite major advances in postnatal care, puerperal sepsis remains a common and potentially preventable cause of direct maternal death. ${ }^{5-8}$ Risk factors for puerperal sepsis include retained products of conception, chorioamnionitis, pelvic abscess, and wound infection are the common causes for severe puerperal sepsis and septic shock in pregnancy and puerperium. ${ }^{5}$

It is reported that major consequences of puerperal sepsis are chronic or acute pelvic inflammatory disease, bilateral tubal occlusion and infertility. ${ }^{9,10}$ After delivery there is susceptibility to invasion of the birth canal by microorganisms for several days which may lead to occurrence of puerperal sepsis when there are births in unhygienic conditions, prolonged rupture of membranes, prolonged labour, postpartum haemorrhage and when vagina examination is done frequently during labour i.e when examinations are done more than 5 times. ${ }^{11}$

Puerperal sepsis is evidenced with clinical signs such as fever above $38^{\circ} \mathrm{C}$, pelvic pain, delayed reduction of the uterine size and smelling vaginal discharge. .,12 $^{9,12}$ Most puerperal sepsis is due to infection of the genital tract by pathogens that colonise the cervix and vagina, 
gain access to amniotic fluid and invade the devitalised uterine tissues. ${ }^{13}$. Bacteria that cause puerperal sepsis includes, Streptococci spp, Staphylococcus spp, Escherichia coli, Clostridium tetani, Clostridium welchii, Chlamydia spp and Gonococcus spp. ${ }^{13}$ Moreover, several studies reported the common aetiologies for puerperal sepsis, including Klebsiella spp, E.coli, S. aureus, Pseudomonas and Enterococci. ${ }^{14-18}$

In Tanzania, few studies have been conducted on puerperal sepsis. The findings have registered a varied puerperal sepsis prevalence ranging from $20 \%$ to $30 \% .{ }^{19,20}$ These two studies have been done in Dar Es Salaam. A previous study done in Mwanza reported a prevalence of $38.9 \% .^{21}$. In the year 2015 , the average national puerperal sepsis prevalence in Tanzania was $29.7 \%{ }^{22}$ which is twice as much as the global puerperal sepsis prevalence which is estimated to be $11 \%{ }^{23}$. To this end, it is therefore important to estimate the prevalence, document factors and causes of puerperal sepsis among postnatal women at Kilimanjaro Christian Medical Centre (KCMC) hospital. The information will help to establish baseline information and identify the gap that can be used during intervention and control of puerperal sepsis. Scarcity of information regarding puerperal sepsis has led to negligence of puerperal sepsis whilst increasing incidences of maternal mortality. The research questions is "what are the factors and causes of puerperal sepsis among postnatal women?".

\section{METHODOLOGY}

\section{Study Design and Area}

This was a descriptive cross-sectional study conducted at KCMC hospital. KCMC is referral hospital located in Kilimanjaro region, Tanzania. Kilimanjaro region is found at the foothills of Mount Kilimanjaro, (www.kcmc.ac.tz). The region has a population of $1,640,087$, with average annual population growth rate of $1.8 \%$, Fertility Rate (TFR) for Kilimanjaro Region is 4.3 (Adjusted) persons per woman in 2013 and Child-woman ratio of 0.46 , maternal mortality rate in Kilimanjaro is 492.1/100,000 live births. ${ }^{24,25}$

The Department of Obstetrics at KCMC serves as a zonal referral centre for complicated obstetric patients. The hospital has an average annual delivery of 3,300, of which $33 \%$ are caesarean deliveries. The labour ward has 4 beds partitioned along the sterile room, with the sterile corridor serving for the extras. There are two operating theatres along the labour ward used for caesarean section services and other obstetric surgical emergencies. ${ }^{25}$

\section{Sample Size Estimation}

The sample size for this study was calculated using the following formula $n=z^{2} p q / d^{2}$. In this equation, $n$ is the sample size, $z$ is the value of the Standard Normal Distribution at $5 \%$ level (1.96), $p$ is the prevalence, $q=1-p$, and $d$ is the precision level (0.05). The prevalence of puerperal sepsis is $12 \%{ }^{26}$. Sample size $=1.96^{2 *} 0.12^{*}(1-$ $0.12) /(0.05)^{2}$. The sample size was $178+10 \%=183$.

\section{Sampling Techniques and Inclusion/Exclusion Criteria}

A systematic sampling technique was used to select the files. The hospital has annual delivery of 3,300, a list of all deliveries in 2015 was requested from the KCMC medical records department. The sampling interval was after every $18^{\text {th }}$ delivery. The study included patient files from January 2015 to December 2015, patients who visited KCMC hospital for obstetrics and gynaecology services. All files with incomplete information were excluded from the study.

\section{Data Collection Method}

Data was collected from the Medical Record Department. Information about isolated causative organism was retrieved from the Laboratory Information System. All required data relevant for the study was recorded using a constructed data extraction sheet. Demographic information such as age, marital status and residence were recorded. Other information such as Haemoglobin level, postpartum haemorrhage, prolonged labour, diabetes, HIV status, mode of delivery and type of bacteria isolated were collected.

\section{Data Analysis}

Data was collected and entered in an excel sheet. Quantitative data was analysed using Statistical Package for Social Science (SPSS) version 22 software (SPSS Inc., Chicago, IL, USA). Descriptive statistical analysis was done to test the effect of each factor on the outcome. Chi-square $(\chi 2)$ was used to compare categorical data while Fisher's exact test was used in cases when expected counts were less than 5. A $P$-value $<.05$ was considered statistically significant.

\section{Definitions}

Mild anaemia was defined as haemoglobin concentration $<11.0-11.9 \mathrm{~g} / \mathrm{dl}$. Moderate to severe anaemia was defined as haemoglobin concentration $\leq 10.9 \mathrm{~g} / \mathrm{dL} .{ }^{27}$

\section{Ethical Consideration}

Ethical approval was obtained from the Kilimanjaro Christian Medical University College Research and Ethics Review Committee (CRERC) with certificate number 2072. Privacy and confidentiality were ensured since the information from patients' file records is kept confidential. Patient names and their corresponding file numbers were not used but instead, individual files identification numbers were generated and used in the data extraction sheet.

\section{RESULTS}

\section{Demographic Characteristics and Prevalence of Puerperal} Sepsis

A total of 183 files were reviewed. Most of the participants $73(39.9 \%)$ were aged between 26 and 35 years, with a mean $( \pm S D)$ age of $30.63( \pm 8.08)$. The majority of participants were married $143(78.1 \%)$ and $93(50.8 \%)$ were residing in rural areas. Furthermore, 86(47\%) were multigravid. The prevalence of puerperal sepsis was $11.5 \%$ (21/183) Table 1.

Bacteria Isolated as Causative Agent of Puerperal Sepsis Among 21 patient files with puerperal sepsis, 14 had results of the isolated causative organism, 2 files had only report of gram stain (gram-negative rods) and 4 files had no record of any isolated organism. The most bacteria species ( $s p p$ ) isolated among women with puerperal sepsis was Staphylococcus spp 50\% (7/21), Escherichia 28.6\% 
$(4 / 21)$ and Streptococcus spp 21.4\% (3/21). Figure 1

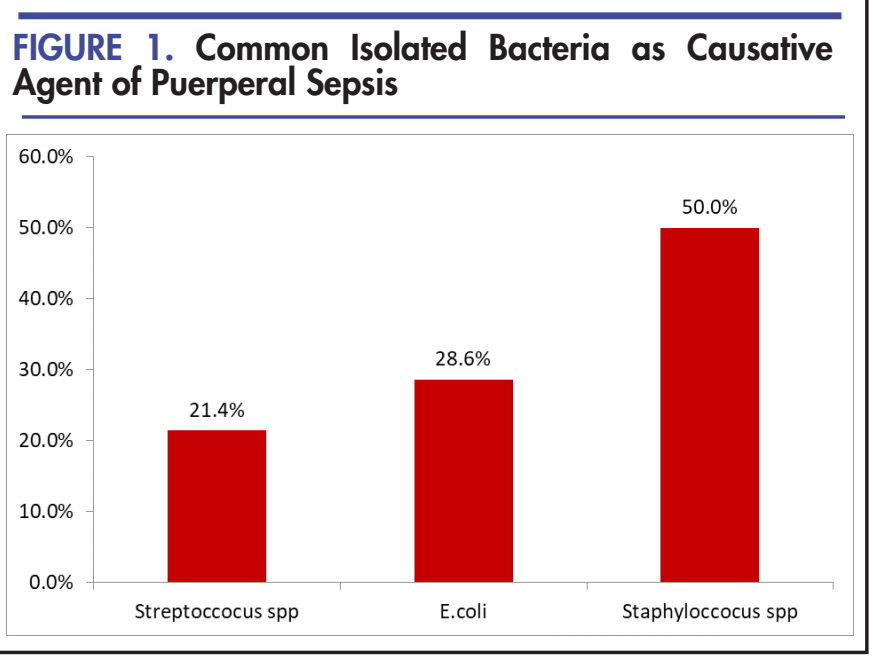

\begin{tabular}{|c|c|c|}
\hline \multicolumn{3}{|c|}{$\begin{array}{l}\text { TABLE 1: Demographic Characteristics of the Participants } \\
(\mathrm{N}=183)\end{array}$} \\
\hline Variable & Frequency $(\mathrm{n})$ & Percent (\%) \\
\hline \multicolumn{3}{|l|}{ Age category } \\
\hline $17-25$ years & 55 & 30.1 \\
\hline $26-35$ years & 73 & 39.9 \\
\hline $36-48$ years & 55 & 30.1 \\
\hline \multicolumn{3}{|l|}{ Marital status } \\
\hline Single & 36 & 19.7 \\
\hline Married & 143 & 78.1 \\
\hline Widow & 4 & 2.2 \\
\hline \multicolumn{3}{|l|}{ Residence } \\
\hline Rural & 93 & 50.8 \\
\hline Urban & 90 & 49.2 \\
\hline \multicolumn{3}{|l|}{ Parity } \\
\hline Primigravid & 66 & 36.1 \\
\hline Multigravid & 86 & 47.0 \\
\hline Grand multigravid & 31 & 16.9 \\
\hline
\end{tabular}

Factors and Causes of Puerperal Sepsis

In this study, the most common factors associated with puerperal sepsis included mode of delivery (caesarean section), postpartum haemorrhage, moderate to severe anaemia, prolonged labour and bacterial infection. There was significant difference in puerperal sepsis proportions among women who had Spontaneous Vaginal Delivery (SVD) $33.3 \%(7 / 21)$ as compared to those with caesarean section $66.7 \%(14 / 21), \chi^{2}=18.49, p=\leq .01$. Women who did not experiences Postpartum Haemorrhage 57.1\% $(12 / 21)$ were more frequent as compared to those who did not have $42.9 \%(9 / 21), \chi^{2}=25.85, p<.001$. The study found that more women with moderate to severe anaemia $61.9 \%(13 / 21)$ were having puerperal sepsis as compared to others, Fischer exact $=8.40, p=.01$. The study shows that puerperal sepsis were more prevalent among women who experienced prolonged labour $76.2 \%$ $(16 / 21)$ as compared to those who did not experience $23.8 \%(5 / 21), \chi^{2}=64.77, p<.001$. Women with puerperal sepsis were more infected with bacteria $90.5 \%(19 / 21)$ as compared to other cause of infection 9.5\% (2/21) such as Candida spp, $\chi^{2}=162, p<.001$. Other factor such as age, residence, parity, pelvic infection during pregnancy, HIV status and Diabetes were not associated with puerperal sepsis, Table 2.

\section{DISCUSSION}

The study aimed to estimate the prevalence, document factors and causes of puerperal sepsis among postnatal women who attended postnatal care in Kilimanjaro Christian Medical Centre Hospital in the year 2015. The prevalence of puerperal sepsis was $11.5 \%$. The findings are relatively comparable with two studies conducted at Muhimbili, Tanzania where the prevalence was $9.2 \%$ in $2011^{28}$ and $11.2 \%$ in $2019 .{ }^{14}$ As well as compared to a recent countrywide study which reported a higher prevalence of $16.7 \% .^{29}$

In the present study, $50 \%$ of commonly isolated bacteria were Staphylococcus spp. The results are higher than other reported findings at Muhimbili, Tanzania $(22.7 \%)^{14}$ and Sudan $(39.5 \%){ }^{16}$ The high prevalence of Staphylococcus spp as the cause of puerperal sepsis might be exogenous where pathogens from nearby skin flora or contact with contaminated non-sterilised instruments or frequent vaginal examination with unwashed hands. ${ }^{30}$ Additionally, the current study did not go further to characterise the Staphylococcus at specie level, although Staphylococcus aureus is more expected than other species. However, in other settings, Staphylococcus epidermidis were isolated among women with puerperal sepsis in other settings. ${ }^{30}$ Although, S. epidermidis is rarely reported but it is a significant nosocomial pathogen, patients may acquire infection when they have compromised immunity. ${ }^{30}$

The present study reports that E.coli $(28.6 \%)$ as the second common cause of puerperal sepsis. This is similar to a study conducted in Harare, which reported E.coli as the commonest cause of puerperal sepsis. ${ }^{15}$ A study conducted at Muhimbili also reported E. coli as one of the causes of puerperal sepsis, accounting for $27.3 \%$ of all isolates. ${ }^{14}$ Variations in the proportion of the commonest bacteria as the cause of puerperal sepsis may be due to differences in the immune status of an individual or population of commensal bacteria. ${ }^{31}$ Furthermore, the differences could be due to study design used, settings as well as variations in bacteriological culture techniques used. $^{2,32}$ It is recommended that in order to have proper infection control measures, it is required that there must be proper education, improvements of guidelines and various technologies and introduction of new clinical guidelines $^{33}$, and continuous improvement of all aspects of maternal health. ${ }^{34}$

In this study, various factor were associated with puerperal sepsis including mode of Delivery (caesarean section), Postpartum Haemorrhage, moderate to severe anaemia and prolonged Labour were statistically associated with puerperal sepsis. Mode of delivery was significantly associated with puerperal sepsis. Data shows that mothers who delivered by SVD were associated with 
TABLE 2: Malaria Prevalence by Age Category

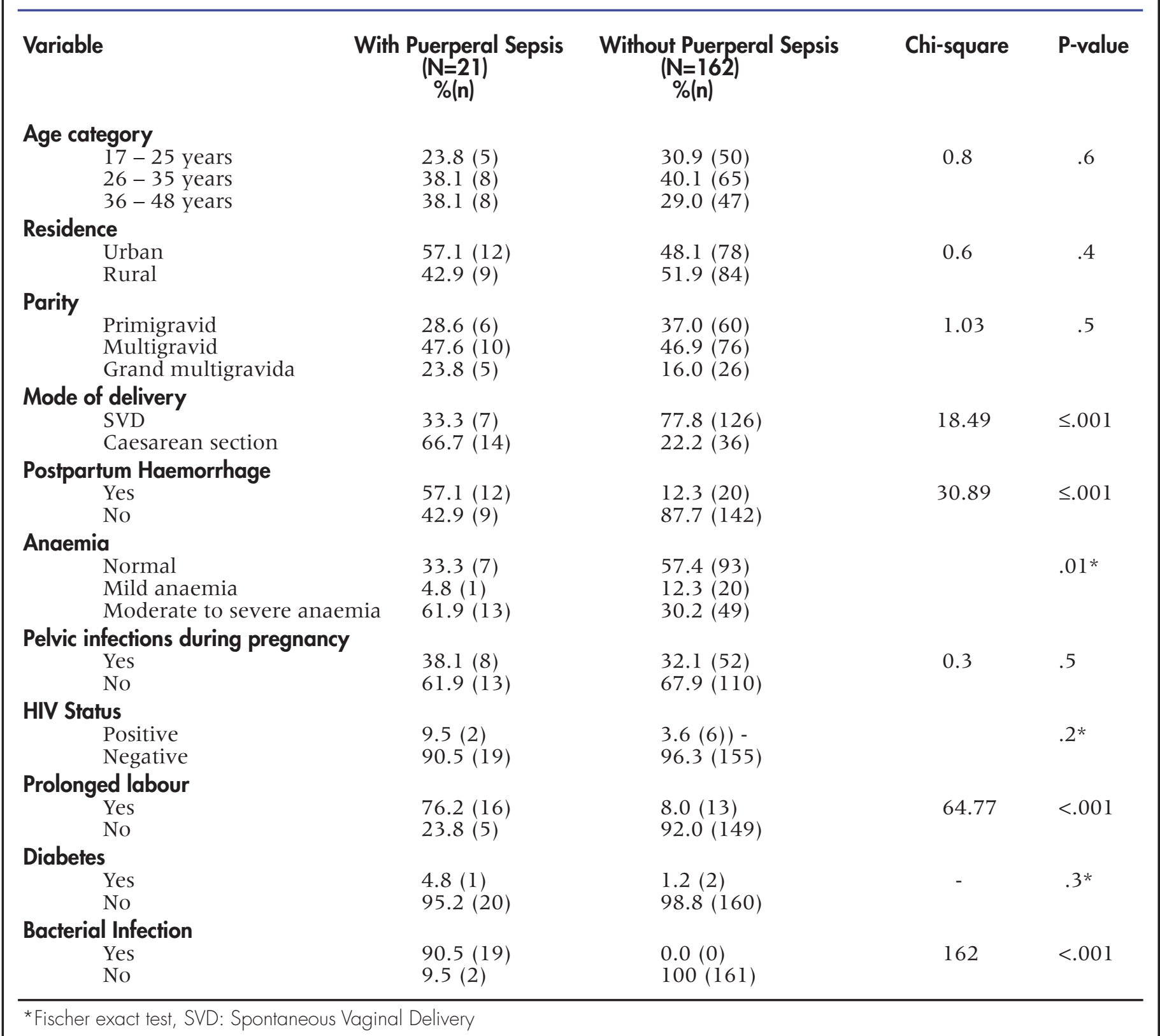

puerperal sepsis when compared to those delivered by caesarean section. The findings are different from a study conducted in Ethiopia ${ }^{2}$ and Nigeria. ${ }^{18}$ Moreover, this is different from a study conducted in Uganda, which reported that Caesarean delivery was independently associated with puerperal sepsis. ${ }^{32}$ This is inconsistent with the study conducted in Ethiopia which reported that participants associated with caesarean section were more less likely to develop puerperal sepsis when compared to those who gave birth through SDV. ${ }^{4}$ In this study, prolonged labour was associated to puerperal sepsis. This is in line with a study by Demisse et al., which reported that participants who experienced labour for 12 to 24 hours and more than 25 hours were 3.1 and 4.7 times respectively more likely to develop puerperal sepsis as compared to those who experienced labour for less than 12 hours. $^{2}$

The present study also revealed that moderate to severe anaemia is among factors that are associated with puerperal sepsis. In Kenya, a study was conducted and reported that anaemia is indirectly associated with puerperal sepsis as well as maternal mortality. ${ }^{35}$ Further research is required to explore the role of anaemia to puerperal sepsis. The study provides valuable information 
that is needed for planning meaningful Reproductive Health Control Programs that aim at reducing the prevalence and associated morbidity of puerperal sepsis among postnatal women attending care at the Hospital.

There is a need for educating the community on hygiene practices especially for postnatal women to reduce cases of puerperal sepsis. Health care providers should be emphasised on working under aseptic conditions to prevent nosocomial infections. During the attendance of antenatal care clinics, hygiene and proper nutrition during and after pregnancy should be taught and emphasised, women should also be enlightened about puerperal sepsis risks and preventive measures.

\section{Strength and Limitation of the Study}

These data signify unique and vigorous information from Kilimanjaro and contribute to the available knowledge on puerperal sepsis among postnatal women in Kilimanjaro region. However, the study is limited with the following; first, the results are limited to Hospital settings, the prevalence and risks of the disease in the community might be different. Secondly, the study was conducted on a small sample size. This may have provided bias on the prevalence and risk of puerperal sepsis, a study with a larger sample size is required.

\section{CONCLUSION}

Puerperal sepsis is prevalent at KCMC hospital. The common risk factors for puerperal infection includes mode of delivery, Postpartum Haemorrhage, prolonged labour, and anaemia. Staphylococcus spp was found to be a predominant isolate which causes puerperal sepsis followed by E. coli and Streptococcus spp.

\section{REFERENCES}

1. WHO. Maternal mortality. World Health Organisation. https://www.who.int/news-room/fact-sheets/detail/maternalmortality\#: : text=94\%25 of all maternal deaths, lives of women and newborns. Published 2019. Accessed November 11, 2020

2. Demisse GA, Sifer SD, Kedir B, Fekene DB, Bulto GA. Determinants of puerperal sepsis among post partum women at public hospitals in west SHOA zone Oromia regional STATE, Ethiopia (institution BASEDCASE control study). BMC Pregnancy Childbirth. 2019;19(1):95. doi:10.1 186/s12884-019-2230-x. Medline

3. $\mathrm{WHO}$. The prevention and management of puerperal infections: report of a technical working group 1992. Geneva: World Health Organization-1 1995. World HealthOrganization. https: / / extranet. who.int/iris/restricted/bitstream/handle/10665/59429/ WHO_FHE_MSM_95.4.pdf; jsessionid-1 1 A60C368B7261AD O28F7AEDBCC C93A2 1 ? sequence-1. Published 1995. Accessed November 10, 2020

4. Atlaw D, Seyoum K, Woldeyohannes D, Berta M. Puerperal sepsis and its associated factors among mothers in University of Gondar referral hospital, Ethiopia, 2017. International Journal of Pregnancy \& Child Birth. 2019;5(5): 190-195. doi:10.15406/ ipcb.2019.05.00175.

5. Refai N, Patil V, Gomaa H. Update in obstetric maternal sepsis. Updat Anaesth..https://www.wfsahq.org/components/ com_virtual_library/media/9b22c9b34cbaOf4beca525cebc b 1 b 3 c8-Update-34-Obs-Maternal-Sepsis.pdf. Published 2019. Accessed November 21, 2020.

6. Bellizzi S, Bassat Q, Ali MM, Sobel HL, Temmerman M. Effect of puerperal infections on early neonatal mortality: A secondary- analysis of six demographic and health surveys. PLoS One. 2017;12(1):e0170856. doi:10.1371/journal. pone.0170856. Medline

7. Turner MJ. Maternal sepsis is an evolving challenge. Int J Gynaecol Obstet. 2019;146(1):39-42. doi:10.1002/iigo.12833. Medline

8 Bonet M, Souza JP, Abalos E, et al. The global maternal sepsis study and awareness campaign (GLOSS): Study protocol. Reprod Health. 2018;15(1):1-17. doi:10.1186/s12978-017-04378. Medline

9. van Dillen J, Zwart J, Schutte J, van Roosmalen J. Maternal sepsis: epidemiology, etiology and outcome. Curr Opin Infect Dis. 2010;23(3):249-254. doi:10.1097/ QCO.Ob013e328339257c. Medline

10. Spera A., Bianco, Simeone, Viceconte, Tosone, Orlando A. Sepsis in Pregnant and Puerperal Women Living in High Income Countries: an Update for Clinicians. J Gynecol Obstet. 2017; 1(023): 1-10.

11. Shamshad SS, Shamsher S, Rauf B. Puerperal sepsis-still a major threat for parturient. J Ayub Med Coll Abbottabad. 2010;22(3): 18-21 Medline.

12. Miller AE, Morgan C, Vyankandondera J. Causes of puerperal and neonatal sepsis in resource-constrained settings and advocacy for an integrated community-based postnatal approach. Int J Gynaecol Obstet. 2013;123(1):10-15. doi:10.1016/i. iigo.2013.06.006. Medline

13. WHO. Education material for teachers of midwifery: midwifery education modules - 2nd ed. Managing Puerperal Sepsis. World Health Organisation. https://apps.who.int/iris/ bitstream/handle/10665/44145/9789241546669_6 eng.pdf? sequence $=6 \& i s A l l o w e d=y$. Published 2008. Accessed November 2, 2019.

14. Kiponza R, Balandya B, Maiigo MV, Matee M. Laboratory confirmed puerperal sepsis in a national referral hospital in Tanzania: etiological agents and their susceptibility to commonly prescribed antibiotics. BMC Infect Dis. 2019;1911):690. doi: 10.1186/s 12879-019-4324-5. Medline

15. Majangara R, Gidiri MF, Chirenje ZM. Microbiology and clinical outcomes of puerperal sepsis: a prospective cohort study. J Obstet Gynaecol. 201 8;38(5):635-641. doi: 10.1080/0144 3615.2017.1399112. Medline

16. Ahmed M, Alsammani M, babiker R. Puerperal sepsis in a rural hospital in Sudan. Mater Sociomed. 2013;25(1):19-22. doi: 10.5455/msm.2013.25.19-22. Medline

17. Knowles SJ, O'Sullivan NP, Meenan AM, Hanniffy R, Robson $M$. Maternal sepsis incidence, aetiology and outcome for mother and fetus: a prospective study. BJOG. 2015;122(5):663-671. doi: 10.1111/1471-0528.12892. Medline

18. Bako B, Audu BM, Lawan ZM, Umar JB. Risk factors and microbial isolates of puerperal sepsis at the University of Maiduguri Teaching Hospital, Maiduguri, North-eastern Nigeria. Arch Gynecol Obstet. 2012;285(4):913-917. doi:10.1007/ s00404-0 1 1-2078-4. Medline

19. Mhada TV, Fredrick F, Matee MI, Massawe A. Neonatal sepsis at Muhimbili National Hospital, Dar es Salaam, Tanzania; aetiology, antimicrobial sensitivity pattern and clinical outcome. BMC Public Health. 2012;12(1):904. doi:10.1186/14712458-12-904. Medline

20. Jabiri A, Wella HL, Semiono A, Sariah A, Protas J. Prevalence and factors associated with neonatal sepsis among neonates in Temeke and Mwananyamala Hospitals in Dar es Salaam, Tanzania. Tanzan J Health Res. 2016; 18(4): 1-7. doi: 10.4314/ thrb.v $18 \mathrm{i} 4.4$ 
21. Kayange $N$, Kamugisha $E$, Mwizamholya DL, Jeremiah $S$ Mshana SE. Predictors of positive blood culture and deaths among neonates with suspected neonatal sepsis in a tertiary hospital, Mwanza- Tanzania. BMC Pediatr. 2010;10(1):39. doi:10.1186/1471-2431-10-39. Medline

22. UNICEF. Maternal and Newborn Health Disparities- Tanzania. UNICEF Data: Monitoring the situation of children and women. https://data.unicef.org/country/tza/. Published 2016. Accessed February 5, 2020.

23. Ali A, Lamont RF. Recent advances in the diagnosis and management of sepsis in pregnancy. [version 1; peer review: 3 approved]. F1000 Res. 2019;8:1546. doi:10.12688/ f1000research. 18736.1. Medline

24. National Bureau of Statistics. Fertility and Nuptiality report 2015. The United Republic of Tanzania. http://www.nbs.go.tz/ nbs/takwimu/census2012/Fertility and Nuptiality Monograph. pdf. Published 2015. Accessed November 12, 2020.

25. Maro EW, Mosha NR, Mahande MJ, Obure J, Masenga G. Ten years trend in maternal mortality at Kilimanjaro Christian Medical Center Tanzania, 2003-2012: A descriptive retrospective tertiary hospital based study. Asian Pac J Reprod. 2016;5(3):214-220. doi:10.1016/i.apir.2016.04.012.

26. Chepchirchir MV. Occurrence and management of puerperal sepsis amongst women of reproductive age (15-49) attending two hospitals in Nandi county, Kenya. 2012.

27. WHO. Haemoglobin concentrations for the diagnosis of anaemia and assessment of severity. World Health Organization. doi:2011

28. Pembe AB, Paulo C, D'mello BS, van Roosmalen J. Maternal mortality at muhimbili national hospital in Dar-es-Salaam, Tanzania in the year 2011. BMC Pregnancy Childbirth. 2014;14(1):320. doi:10.1186/1471-2393-14-320. Medline

29. Bwana VM, Rumisha SF, Mremi IR, Lyimo EP, Mboera LEG. Patterns and causes of hospital maternal mortality in Tanzania: A 10-year retrospective analysis. PLoS One. 2019; 14(4):e0214807. doi: 10.1371/iournal.pone.0214807. Medline

30. Alsammani MA, Babiker RA, Ahmed MI. Microbial profile in women with puerperal sepsis in Gadarif State, Eastern Sudan. Ann Trop Med Public Health. $2013 ; 6(4): 460-464$. doi: 10.4103/1755-6783.127801.

31 . Monin L, Whettlock EM, Male V. Immune responses in the human female reproductive tract. Immunology. 2020; 160(2): 106-1 15. doi:10.1111/imm.13136. Medline

32. Ngonzi J, Bebell LM, Fajardo Y, et al. Incidence of postpartum infection, outcomes and associated risk factors at Mbarara regional referral hospital in Uganda. BMC Pregnancy Childbirth. 2018;18(1):270. doi:10.1186/s12884-018-1891-1. Medline

33. Larson EL, Quiros D, Lin SX. Dissemination of the CDC's Hand Hygiene Guideline and impact on infection rates. Am J Infect Control. 2007;35(10):666-675. doi:10.1016/i. ajic. 2006. 10.006. Medline

34. Khaskheli M, Baloch S, Baloch AS. Risk factors and complications of puerperal sepsis at a tertiary healthcare centre. Pak J Med Sci. 2013;29(4):972-976. doi:10.12669/pims.294.3389. Medline

35. Desai M, Phillips-Howard PA, Odhiambo FO, et al. An analysis of pregnancy-related mortality in the KEMRI/CDC health and demographic surveillance system in western Kenya. PLoS One. $2013 ; 8(7): e 68733 . \quad$ doi:10.1371/journal.pone.0068733. Medline

\section{Peer Reviewed}

Acknowledgement: The authors wish to acknowledge all patients and KCMC hospital

Competing Interests: None declared.

Funding: This survey did not receive any funding

Received: 30 Dec 2019; Accepted: 19 Nov 2020

Cite this article as Kajeguka CD, Mrema NR, Mawazo A, Malya R, Mgabo RM. Factors and causes of Puerperal Sepsis in Kilimanjaro, Tanzania: A descriptive study among postnatal women who attended Kilimanjaro Christian Medical Centre. East Afr Health Res J. 2020;4(2):158-163. https://doi. org/10.24248/eahrj.v4i2.639

(C) Kajeguka et al. This is an open-access article distributed under the terms of the Creative Commons Attribution License, which permits unrestricted use, distribution, and reproduction in any medium, provided the original author and source are properly cited. To view a copy of the license, visit http:// creativecommons.org/licenses/by/4.0/. When linking to this article, please use the following permanent link: https://doi. org/10.24248/eahrj.v4i2.639 